\title{
SISTEM INFORMASI PENGAJUAN KLAIM PESERTA JAMINAN KESEHATAN (JKN) BERBASIS WEB DI RUMAH SAKIT Dr. M.M. DUNDA LIMBOTO
}

Marlin Lasena 1, Abas Abuniy 2

12 STMIK Ichsan Gorontalo

Jurusan Sistem Informasi, STMIK Ichsan Gorontalo

Lantai 2, Kampus $1 \mathrm{Jl}$. Ahmad Nadjamudin e-mail :

Imarlinlasena@gmail.com, zgoen_abas@yahoo.com

\begin{abstract}
Changes in technology currently affects all aspects including health, in order to increase effectiveness and efficiency in the service, it is necessary to change to the old system to facilitate the patient and the parties Health service Provider in conducting health service process. Everyone has the right to live prosperous lives, reside, and gain a good and healthy environment and deserve health care "and" everyone has the right to social security that allows the development of himself. Wholly as a beneficial human being "this research uses Research and Development methods where the application is designed using programming language software Android, PHP and HTML. The results concluded that by the existence of information system of the claim submission of health care participants, the party hospital Dr. MM. Dunda Limboto can manage the file administration data of the claims of patients with more efficiently
\end{abstract}

Keywords: Mobile Learning, Android, HTML and PHP

Abstrak - Perubahan Teknologi saat ini mempengaruhi seluruh aspek termasuk dalam bidang kesehatan, dalam rangka meningkatkan efektifitas dan efisiensi dalam pelayanan, maka perlu dilakukan perubahan terhadap sistem lama untuk mempermudah pihak pasien dan pihak Pemberi Pelayanan Kesehatan (PPK) dalam melakukan proses pelayanan kesehatan. Setiap orang berhak hidup sejahtera lahir dan batin, bertempat tinggal, dan mendapatkan lingkungan hidup yang baik dan sehat serta berhak memperoleh pelayanan kesehatan" dan "Setiap orang berhak atas Jaminan Sosial yang memungkinkan pengembangan dirinya secara utuh sebagai manusia yang bermanfaat" Penelitian ini menggunakan metode Research and Development dimana aplikasi dirancang menggunakan software bahasa pemograman Android, PHP dan HTML. Hasil penelitian menyimpulkan bahwa dengan adanya sistem informasi pengajuan klaim peserta jaminan kesehatan, pihak Rumah Sakit Dr. MM. Dunda Limboto dapat mengelola data administrasi berkas klaim pasien dengan lebih efiesien.

Kata Kunci- Mobile Learning, Android, HTML dan PHP manusia yang bermanfaat". Amanat tersebut juga tertera pada Pasal 34 ayat (3) yang berisi "Negara bertanggung jawab atas penyediaan fasilitas pelayanan kesehatan dan fasilitas pelayanan umum yang layak". Untuk mewujudkan komitmen global

I. Pendahuluan

Perkembangan teknologi informasi sangatlah pesat. Beberapa aplikasi berbasis android pun telah banyak diciptakan dan digunakan dalam berbagai bidang. Penggunaan ponsel pintar telah popular disemua kalangan tidak hanya digunakan dalam berkomunikasi dan hiburan, tetapi dapat digunakan sebagai media untuk mengakses internet dalam mengirim dan menerima data. Laju informasi yang pesat memberikan dampak penggunaan teknologi informasi secara besar-besaran pada instansiinstansi dalam rangka meningkatkan kinerja instansi yang ada [1].

Setiap orang berhak hidup sejahtera lahir dan batin, bertempat tinggal, dan mendapatkan lingkungan hidup yang baik dan sehat serta berhak memperoleh pelayanan kesehatan" dan "Setiap orang berhak atas Jaminan Sosial yang memungkinkan pengembangan dirinya secara utuh sebagai dan konstitusi di atas, pemerintah bertanggung jawab atas pelaksanaan jaminan kesehatan masyarakat melalui Jaminan Kesehatan Nasional (JKN) bagi kesehatan perorangan. Usaha ke arah itu sesungguhnya telah di rintis pemerintah dengan menyelenggarakan beberapa bentuk jaminan sosial di bidang kesehatan [2].

Secara operasional, pelaksanaan Jaminan Kesehatan Nasional (JKN) dituangkan dalam Peraturan Pemerintah dan Peraturan Presiden, antara lain: Peraturan Presiden Nomor 12 Tahun 2013 tentang Jaminan Kesehatan; Peta Jalan Jaminan Kesehatan Nasional (Roadmap JKN); dan Peraturan

Pemerintah Nomor 101 Tahun 2012 tentang

Penerima Bantuan Iuran (PBI) [2].

Penyelenggara upaya jaminan kesehatan di Puskesmas dan Rumah sakit juga tidak lepas dari peran serta rekam medis disetiap unit pelayanan 
kesehatan. catatan tersebut yang kemudian akan diolah oleh rumah sakit dan puskesmas untuk disampaikan di dinas kesehatan untuk mendapatkan jaminan kesehatan nantinya. Dinas kesehatan akan memperoleh data dari setiap puskesmas dan rumah sakit, untuk diolah agar dapat mendistrbusikan bantuan jaminan kesehatan bagi keluarga yang tidak mampu dengan baik dan tepat guna serta menghindari manipulasi data dalam penyaluran dan pengiriman data.

Berdasarkan penelitian awal yang dilakukan ditemukan bahwa selama ini mulai dari proses Pemberian Pelayanan Kesehatan (PPK) dilakukan dengan cara mendatangi langsung loket pendaftaran peserta JKN yang sering kali terjadi antrian panjang dikarenakan banyaknya masyarakat yang ingin mendapatkan pengobatan tiap harinya. Berdasarkan data diperoleh bahwa rata-rata setiap harinya masyarakat yang ingin berobat mencapai 100 orang atau lebih, faktor lain yang menghambat adalah jumlah bagian pelayanan yang terbatas ditambah dengan proses pengadmintrasian berkas klaim yang dilakukan dalam metode pencatatan dalam kartu kontrol. Keadaan seperti ini memperlambat proses pengajuan klaim yang dapat berakibat proses pembayaran klaim menjadi tertunda. Maka dari itu perlu adanya perubahan menjadi sistem pengajuan terkomputerisasi sesuai dengan kebutuhan yang diperlukan. Untuk itu dibutuhkan Perancangan sistem informasi pengajuan klaim secara online. Agar dapat mempermudah pihak pasien dan pihak Pemberi Pelayanan Kesehatan (PPK) dalam melakukan proses data klaim secara cepat.

\section{METODE PENELITIAN}

\section{A. Metode Penelitian}

Penelitian ini menggunakan metode Research and Development. Metode ini didefinisikan sebagai metode penelitian yang digunakan untuk menghasilkan sebuah pelayanan prima dan menguji keefektifan pelayanan tersebut. Secara sistematis Research and Development membagi metode menjadi 3 bagian dalam penelitian yaitu:

a. Deksriptif. Digunakan dalam studi awal untuk menghimpun data kondisi yang ada yaitu perbandingan kondisi produk yang sudah ada dan yang akan dikembangkan, kondisi pihak pengguna, kondisi faktor pendukung dan penghambat.

b. Evaluatif. Digunakan untuk mengevaluasi proses uji coba pengembangan suatu produk.

c. Eksperimen. Digunakan untuk menguji keampuhan produk yang dihasilkan.

Metode Research and Development digunakan peneliti untuk membangun aplikasi Sistem Informasi dalam pelayanan kesehatan yang efektif, efisien dan bemutu di RSUD Dr.MM.Dunda Limboto. melakukan pengecekan terhadap data - data yang sudah masuk dan melaporkan berkas - berkas klaim yang sudah masuk ke dalam sistem, dan melakukan pengajuan klaim melalui sistem dari kementrian kesehatan

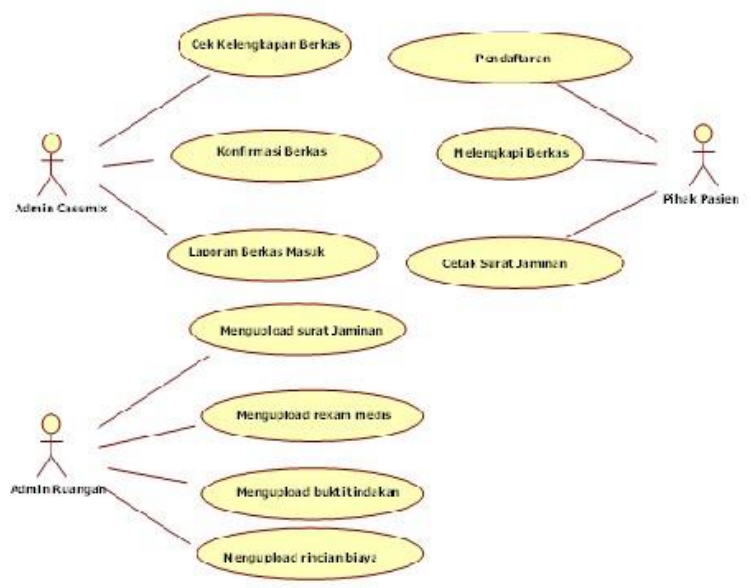

Gambar 1. Sistem yang diusulkan

B. Perancangan Sistem

Tahapan dalam proses perancangan sistem adalah sebagai berikut:

1. Menentukan objek penelitian.

Telah dibahas sebelumnya bahwa objek penelitian akan dilakukan pada RSUD Dr. MM. Dunda Limboto Kab. Gorontalo, Provinsi Gorontalo

2. Studi Pustaka

Pengumpulan data dengan cara membaca serta mempelajari dokumen-dokumen,jurnal, buku, dan literature yang berhubungan dengan objek penelitan guna mendapatkan teori dan konsep.

3. Pengumpulan data dan informasi Pengumpulan data dan informasi diperoleh secara valid karena berasal dari sumber-sumber yang terpercaya yang telah diteliti secara cermat.

4. Analisa Sistem yang Berjalan

Kelemahan pada sistem yang berjalan yaitu seorang Peserta JKN harus antri dalam melakkukan pendaftaran setelah itu baru bisa datang ke tempat prakteknya dokter yang ingin di tuju, sehingga memerlukan waktu yang lebih lama dalam proses pelayanan dan juga dalam pengadministrasian klaim dimana pihak administrasi ruangan harus mengadakan duplikat berkas - berkas untuk diberikan ke ruangan rekam medic dan juga untuk tim Casemix.

5. Analisa Kebutuhan Sistem

Analisa kebutuhan sistem dilakukan untuk mengetahui apa saja yang dibutuhkan sistem untuk dapat berjalan.

6. Perancangan Database Teknik perancangan database menggunakan MySql

\section{Analisis system yang diusulkan}

Langkah awal dengan Peserta JKN melakukan login atau registrasi terlebih dahulu apabila belum memiliki akun, kemudian Peserta JKN mengisi biodata dan mengupload berkas, dan pergi ke poliklinik yang dituju. Kemudian admin ruangan melakukan login dan memvalidasi data. Setelah itu melengkapi data pengajuan klaim dengan mengupload berkas berkas klaim kedalam sistem, kemudian pihak casemix

\section{HASIL DAN PEMBAHASAN}

1. Hasil Pembahasan

Berikut merupakan tampilan Graphic User Interface dari sistem yang diusulkan :

1. Halaman Beranda 


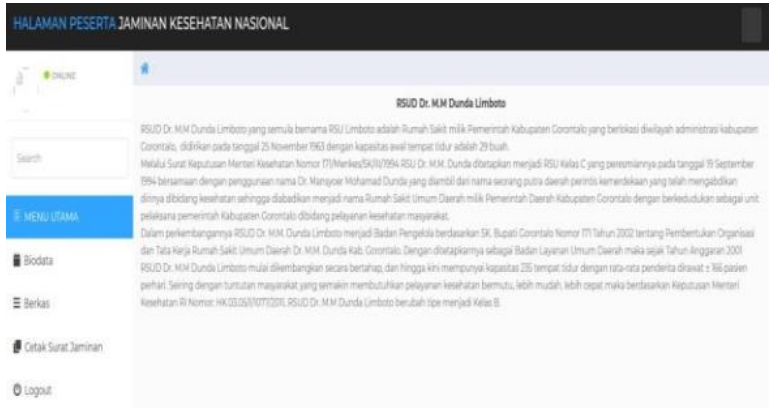

Gambar Halaman Beranda

Gambar diatas merupakan halaman beranda dalam system yang terdiri dari sejumlah menu yang bias diakses oleh peserta ataupun admin.

\section{Halaman Registrasi Peserta}

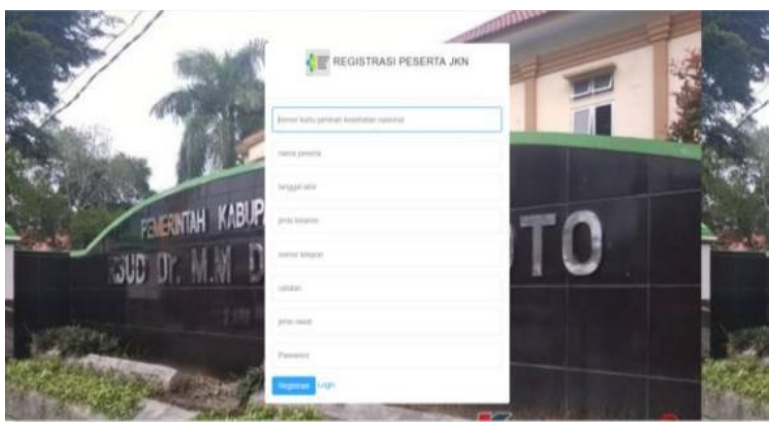

Gambar 3. Halaman Registrasi Peserta

Gambar diatas merupakan halaman untuk registrasi peserta JKN yang belum memiliki akun

3. Halaman Login Peserta

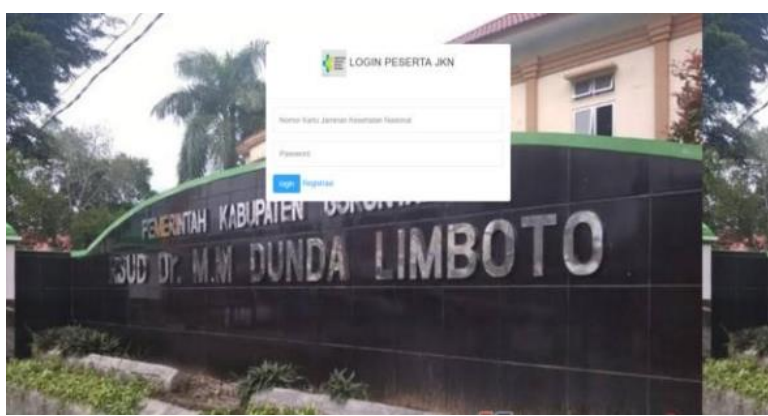

Gambar 4. Halaman Login Peserta

Tampilan diatas merupakan tampilan login peserta, untuk login peserta harus memasukkan username dan password
4. Halaman Upload Berkas

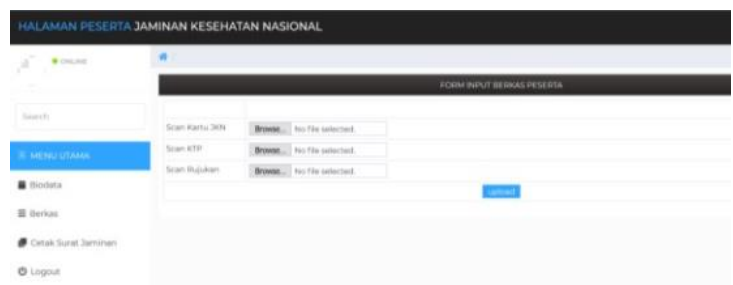

Gambar 5. Halaman Upload Berkas

Tampilan halaman gambar diatas adalah halaman untuk menguplod berkas peserta

5. Tampilan Login Admin Ruangan

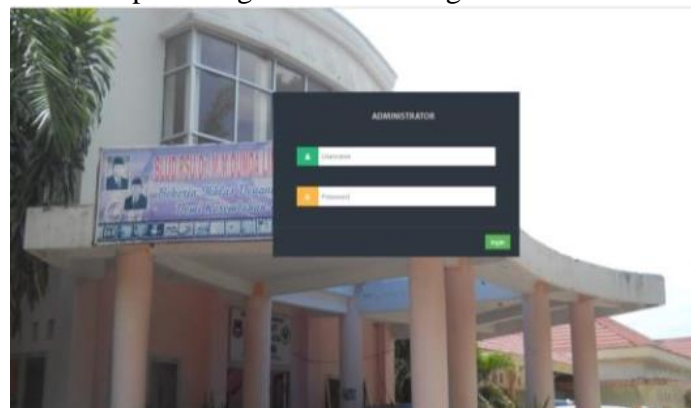

Gambar 7. Daftar Peserta

Tampilan gambar diatas merupakan halaman login khusus admin

6. Halaman Daftar Peserta

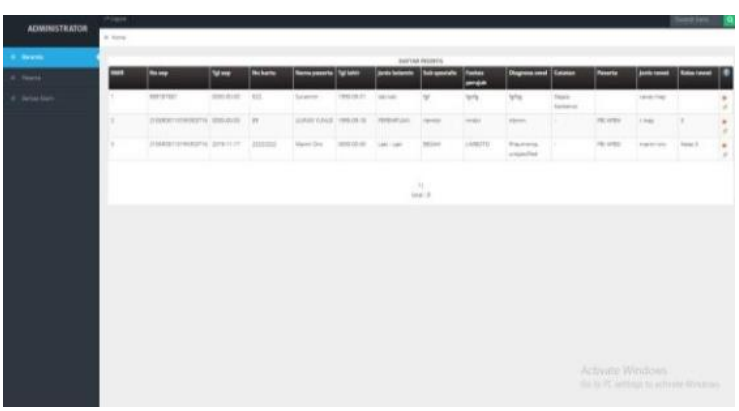

Tampilan Gambar berikut memuat daftar peserta JKN yang telah melakukan login, admin dapat melakukan pengecekan berkas dari daftar ini. 


\section{Halaman Validasi Data}

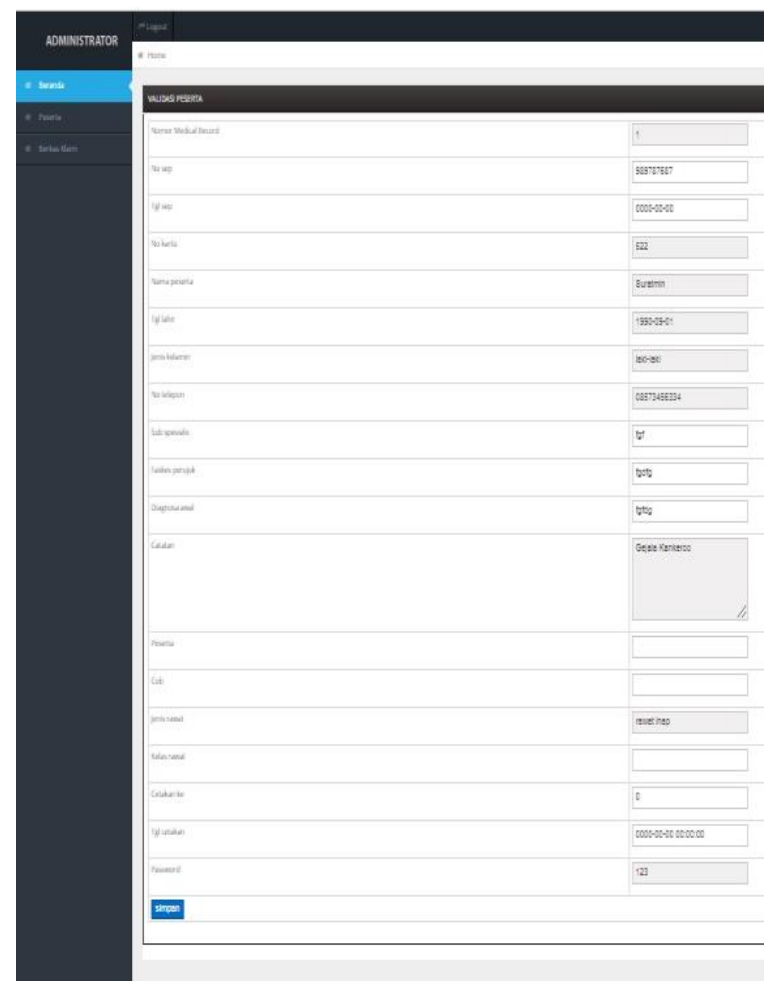

Gambar 8. Halaman Validasi Data peserta

Tampilan gambar diatas merupakan halaman validasi data peserta. Halaman ini hanya bisa diakses oleh admin.

8. Halaman Laporan Berkas Masuk

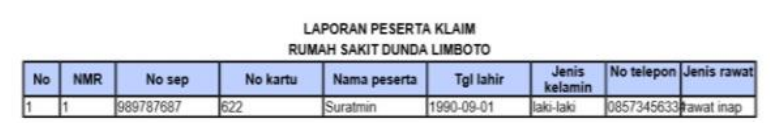

Gambar 9. Laporan Berkas Masuk Tampilan gambar diatas adalah laporan berkas masuk yang bisa diakses oleh admin, laporan dapat dibuat dalam perbulan, per triwulan, dan persemester

\section{KESIMPULAN DAN SARAN}

\section{Kesimpulan}

Penelitian ini menyimpulkan bahwa sistem informasi pengajuan klaim peserta Jaminan kesehatan dapat membantu Rumah Sakit dalam meningkat pemberian pelayanan

$$
\text { kesehatan untuk peserta JKN serta }
$$
mempermudah dalam pengadministrasian berkas - berkas Klaim Rumah Sakit Umum Dr. M.M Dunda Limboto.

\section{SARAN}

Penelitian ini masih terdapat kekurangan dan perlu diadakan pengembangan dalam rangka memberikan pelayanan terbaik bagi peserta Jaminan kesehatan terutama dalam menyelesaikan masalah administrasi dengan cepat, oleh karena itu disarakan kepada peneliti selanjutnya dapat mengembangkan penelitian dengan menggunakan sistem online atau terintegrasi dengan jaringan sehingga penggunaan aplikasi tidak hanya bisa dirumah sakit Dr. MM.Dunda Limboto saja tetapi bisa diakses ke rumah sakit yang ada diprovinsi Gorontalo.

\section{REFERENSI}

[1] M. L. Safira, "Sistem Informasi Manajemen Rumah Sakit Berbasis Web Pada Rumah Sakit Umum Daerah Bolaang Mongondow Utara," Kota Gorontalo, 2017.

[2] . D. H. K. M. A. Kasemin, Agresi Perkembangan Teknologi Informasi, Rawamangun, Jakarta: KENCANA (Devisi dari PRENAMEDIA Group), 2015.

[3] R. Witanto and H. H. Solihin, "Hasil penelitian dari [4]. Dengan judul Perancangan Sistem Informasi Penerimaan Siswa Baru Berbasis Web. Perancangan sistem informasi berbasis web ini tidak membahas mengenai proses pembayaran administrasi pendaftaran sehimgga tidak ada kaitannya dengan b," Jurnal Infotronik, vol. 1, no. 2548-1932, p. 1, 2016.

[4] Sulfina, "Sistem Informasi Pelayanan Kunjungan Neonatus Berbasis Android Pada Kec. Togean (Sulawesi Tengah)," Gorontalo, 2019.

[5] J. Hutahean, Konsep Sistem Informasi, Yogyakarta: CV BUDI UTAMA, 2014.

[6] A. Kadir, Pengenalan Sistem Informasi, Yogyakarta: Andi, 2003.

[7] A.-B. B. Ladjamudin, Analisis dan Desain Sistem Informasi, Yogyakarta: Graha Ilmu, 2005.

[8] K. S. Haryana, "Pengembangan Perangkat Lunak Dengan Menggunakan PHP," Jurnal Computech \& Bisnis, vol. 2, no. 1978-9629, p. 1, 2008.

[9] H. Yuliansyah, "Perancangan Replikasi Basis Data MySQL Dengan Mekanisme Pengamanan Menggunakan SSL Encryption," Jurnal Informatika, vol. 8, p. 1, 2014. 